\title{
An Alternative Approach in Treating Orofacial Pain: A Pilot Study of 24 Patients
}

\author{
Vela D Desai, Shruti Sharma, Neelkant Patil
}

\begin{abstract}
Objectives: Alternative dentistry is the ever increasing topic of interest in order to unlock the secrets of age old techniques used in the treatment of various diseases. This study was done to relieve pain by alternative therapy and compare four different techniques and their effectiveness in relieving pain.
\end{abstract}

Materials and methods: The study comprised of 24 subjects on whom four different techniques namely coconut oil therapy, reflexology, warm cold ice pack and ginger therapy were tried.

Results: It was observed that coconut oil therapy was the best analgesic and warm cold ice pack was fastest acting analgesic.

Conclusion: We can efficiently use alternative medicines in treating different levels of pain and reduce the burden of analgesics and its side effects.

Keywords: Coconut oil therapy, Reflexology, Warm cold ice pack, Ginger therapy, Orofacial pain.

How to cite this article: Desai VD, Sharma S, Patil N. An Alternative Approach in Treating Orofacial Pain: A Pilot Study of 24 Patients. World J Dent 2012;3(3):255-256.

\section{Source of support: Nil}

Conflict of interest: None declared

\section{INTRODUCTION}

We all are very much aware of the fact that dental pain is the most common symptom that brings patient to a dentist. As a result, in order to relieve the pain we prescribe analgesics.

Pain ranges from mild to moderate to more severe and so is the dose of analgesics. The major concern we have today is dependence on analgesics. A part from this, their are so many side effects, like nausea, vomiting, peptic ulcers, etc. ${ }^{1}$ The question that does not any more remain unanswered is whether we can reduce the burden of analgesics and still relieve the pain. The answer to is 'A lternative medicine'.

A lternative medicine is any healing practice that does not fall within the realm of conventional medicine. The $\mathrm{N}$ ational Center for Complementary and Alternative Medicine (NCCAM) defines CAM as 'a group of diverse medical and healthcare systems, practices and products, that are not currently part of conventional medicine.' ${ }^{2}$

The current accepted modern medicine or allopathy has gradually developed over the years by scientific and observational efforts of scientists. However, the basis of its development remains rooted in traditional medicine and therapies. The history of medicine includes many ludicrous therapies. N evertheless, ancient wisdom has been the basis of modern medicine and will remain as one important source of future medicine and therapeutics. To unlock the secrets of ancient herbal remedies, study was done to relieve pain by alternative therapy and compare four different techniques and their effectiveness.

\section{MATERIALS AND METHODS}

The study was constituted 24 subjects ( 12 males and 12 females) in a period of 2 months in the department of oral medicine and radiology, Jaipur Dental College, Rajasthan.

Patients having odontogenic pain (chronic pain confirmed radiographically) and age ranging from 30 to 50 years were include in the study. Patients who were having any systemic illness or those who had taken medication for relieving pain or undergone any dental treatment were excluded from the study.

Subjects were carefully selected keeping in mind inclusion as well as exclusion detail. C ase history was taken with special reference to the pain. A fter taking the consent of the patient pain intensity was measured by using visual analog scale.

Subjects were randomly divided in four groups and each group having six patients on whom four different therapies were performed.

First group was clove and coconut oil therapy. The active ingredient in clove is eugenol $\mathrm{oil}^{3}$ and coconut is caprylic acid $^{4}$ both of which have analgesic effect, patients were asked to crush 1 clove in $10 \mathrm{ml}$ of coconut oil and heat it and apply on offending tooth.

Second therapy used was warm and ice pack. This aims to numb the pain and provide with anal gesic effect. ${ }^{4}$ Patients were asked to take tw 0 bowls of water; one filled with warm water and other one with ice cold water. Patient was asked to dip cotton in warm water, apply it on offending tooth and simultaneously dip in cold water and apply.

Third therapy was hand reflexology. This method follows the principle that reflexes on right side of body are controlled by left cortex and left side reflexes and controlled by the right one. Similarly, if the pain was on the right teeth region than patients were asked to dip their left hand in the ice chilling water and if pain was on the left side than right hand was immersed in the water. 
Fourth therapy was ginger therapy. The active ingredient is gingerol ${ }^{4}$ which is a potent analgesic. Patients were advised to keep a fresh piece of ginger and bite it with the offending tooth.

To confirm the effectiveness, each therapy was done 3 times a day and follow-up was done just after performing the therapy and after 3 days by using visual analog scale for all subjects. The data obtained was collected, assesed and tabulated.

\section{RESULTS}

The time taken to relieve pain was noted for each therapy. It was observed that fastest acting analgesic was warm and cold water pack which took 1 minute ( $\mathrm{mts}$ ) to relieve pain, whereas coconut and clove oil therapy, hand water therapy and ginger therapy took approximately 1.8, 5.3 and $10.5 \mathrm{mts}$ respectively (Graph 1 ).

It was also observed from that coconut and clove oil therapy relieved pain for much longer time which is around $6.6 \mathrm{mts}$ as compared to warm/cold pack, hand therapy,

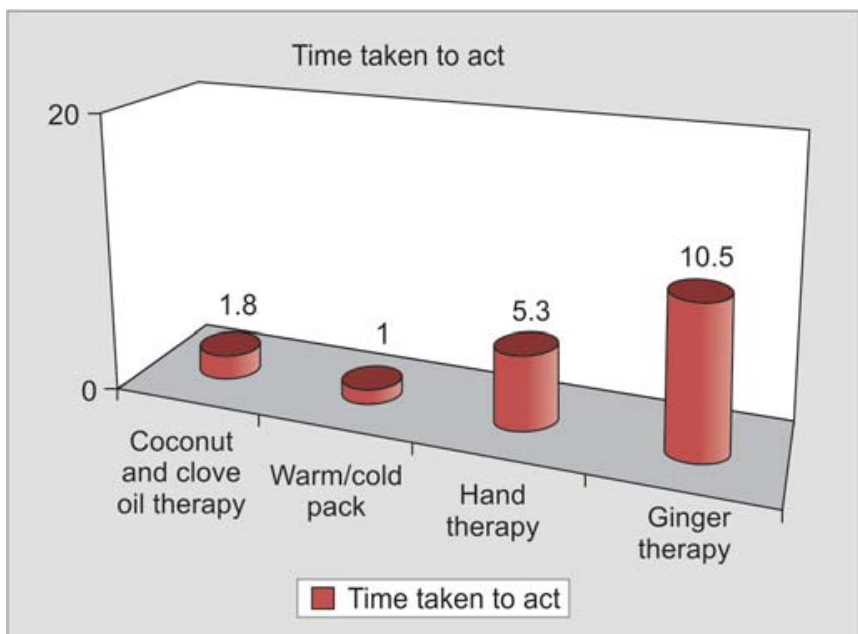

Graph 1: Time period for which pain relieved versus therapy used

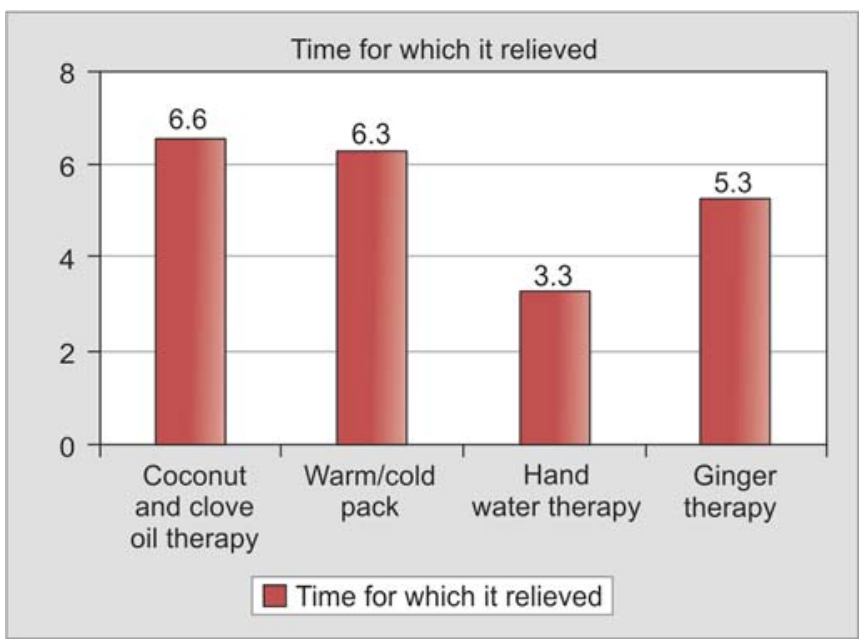

Graph 2: Persistence of pain free interval for each therapy used ginger therapy which relieved for $6.3,3.3$ and 5.3 mts respectively (Graph 2 ).

\section{DISCUSSION}

Now a days individuals utilize mainstream medicine for diagnosis and basic information, while turning to alternatives for therapy or health-enhancing measures. Studies indicate that al ternative approaches are often used in conjunction with conventional medicine. ${ }^{5}$ Complementary therapies are often used in palliative care or by practitioners attempting to manage chronic pain in patients.

A ccess to conventional medicines is severely restricted by lack of resources and poverty. ${ }^{3}$ A lternative remedies, can be readily used for such patients who cannot afford to buy conventional medicines. People are becoming aware of side effects that range from nausea, vomiting to serious side effects like ulcers and have nondrug approach toward treatment. These therapies pose a wide range of uses in oro facial pain. A Iternative medicines remain to be a good modality because it not only helps in relieving the pain but also takes care of psychological component of pain by incorporating patient education, physical therapies, relaxation techniques and psychosocial counseling in the treatment. $^{5}$

In this study, it was observed that these therapies effectively replaced analgesics. Similar studies can be performed on large number of subjects to analyze the accurate results of different techniques in different age groups and relieve mankind from various types of pain.

\section{REFERENCES}

1. Ernst E. Complimentary medicines; common misconceptions. J ournal of Royal Society of M edicine 1991;88(5):244-47.

2. Cochrane complimentary medical field: Cochrane collaboration.

3. A stin JA. Why patients use al ternative medicine-Results of national study. Journal of A merican Medical A ssociation 2001;279(19):1548-53.

4. Ernst, et al. Efficacy of herbal medicines-A n overview. J ournal of Clinical Pharmacology 2000;19(4):405-09.

5. Hudson Complementary and A Iternative medicines impact on dentistry OOOOE; 2004;98(2):137-45.

\section{ABOUT THE AUTHORS}

\section{Vela D Desai (Corresponding Author)}

Professor and Head, D epartment of O ral M edicine and R adiology, Jai pur Dental College, Jaipur, Rajasthan, India, e-mail: veladesai@ hotmail.com

\section{Shruti Sharma}

Postgraduate Student, Department of Oral M edicine and Radiology J aipur D ental College, Jaipur, Rajasthan, India

\section{Neelkant Patil}

Senior L ecturer, Department of Oral M edicine and Radiology, J ai pur Dental College, Jaipur, Rajasthan, India 